East African Medical Journal Vol. 86 No. 11 November 2009

ADEQUACY OF BLOOD PRESSURE CONTROL AND LEVEL OF ADHERENCE WITH ANTIHYPERTENSIVE THERAPY

L. Achieng', MBChB, Senior House Officer, Department of Clinical Medicine and Therapeutics, M. D. Joshi, MBChB, MMed, MPH, FACC, Senior Lecturer and Director, Clinical Epidemiology Unit, E. N. Ogola, MBChB, MMed, FACC, Associate Professor, and E. Karari, MBChB, MMed, Lecturer, Department of Clinical Medicine and Therapeutics, College of Health Sciences, University of Nairobi, P.O. Box 19676-00202, Nairobi, Kenya

Request for reprints to: Dr. L. Achieng', Department of Clinical Medicine and Therapeutics, College of Health Sciences, University of Nairobi, P.O. Box 2304 - 00202, Nairobi, Kenya

\title{
ADEQUACY OF BLOOD PRESSURE CONTROL AND LEVEL OF ADHERENCE WITH ANTIHYPERTENSIVE THERAPY
}

\author{
L. ACHIENG', M. D. JOSHI, E. N. OGOLA and E. KARARI
}

\begin{abstract}
Objectives: To determine the adequacy of blood pressure (BP) control and level of adherence to pharmacotherapy in hypertensive out-patients.

Design: Cross-sectional study.

Setting: General medical outpatient clinics at a tertiary referral hospital, Kenyatta National Hospital.

Subjects: Hypertensive with at least one documented renewal of prescription.

Main outcome measure: Adequacy of BP control and level of adherence by the HillBone score.

Results: Of 783 patients screened over a six month period, $575(73 \%)$ met the inclusion criteria and 264 were randomly recruited; $67 \%$ were female; mean age was 57.3 years; mean duration of hypertension was 6.75 years (range six months to 31 years);21.6\% had normal BMI. Knowledge of lifestyle measures for BP control was weight loss 50\%, exercise $54 \%$ and salt restriction $80 \%$. Number of antihypertensives prescribed were $35.2 \%$ two drugs, $36.6 \%$ three drugs and $14.9 \%$ on four or more drugs; with drugs class being thiazide diuretics $64.1 \%$, B-blockers $55.7 \%$, calcium channel blockers $55.3 \%$ and angiotensin system inhibitors at $50.4 \%$. Sixty eight $(26 \%)$ had adequate BP control and $114(58.5 \%)$ of those with inadequate BP control had BP of $\geq 160 / 100 \mathrm{mmHg}$. Eighty four $(31.8 \%)$ of the patients were fully adherent to antihypertensive therapy. Non adherence was not significantly associated with any socio-demographic factors. Poor $B P$ control was significantly associated with non adherence $\left(p=0.006, r^{2}=0.54\right.$ SBP, 0.63 $\mathrm{DBP})$, obesity $(\mathrm{p}=0.03)$, and increasing number of medications $(\mathrm{p}=0.012 \mathrm{DBP}$ and 0.038 SBP);other factors included obesity, suboptimal dosing and suboptimal therapeutic combinations.

Conclusion: We document poor BP control in $75 \%$ of our treated hypertensive patients and this is largely due to non adherence, with other associated factors being obesity, suboptimal drug combinations and doses.
\end{abstract}

\section{INTRODUCTION}

Hypertension in sub-Saharan Africa is a wide spread problem of immenseeconomicimportance on account of its increasing prevalence, particularly in urban areas, its frequent under diagnosis, treatment and control and the severity of its complications (1). It is a major modifiable risk factor for cerebrovascular, cardiovascular and renal disease and effective treatment reduces the mortality and morbidity related to end-organ damage.

Despite availability of effective medical therapy for hypertension, only about $31 \%$ of persons globally with hypertension are adequately controlled. This has also been documented in developed countries where there has been little progress in the quality of control of hypertension. In mainly population-based surveys carried out between 1986-1998, the control of hypertension in adults aged 35-64 years was $28 \%$ in North America and about 10\% in Europe (2); with an increase in controlled patients in the USA to $49 \%$ in 1999 (3). In Australia, a retrospective study showed level of control to be $33 \%$ of treated patients (4).

Astudy in Ashanti, Ghana found only 2.8\% of 291 patients studied had their BP adequately controlled whereas in Accra, the level was 6.2\% (5). In Tanzania. a study of the urban population of Dar es Salaam found good BP control in 7-13\% (6). 
Various explanations have been proffered to explain why such a large percentage of patients have uncontrolled hypertension including secondary hypertension and endogenous resistance to treatment. However, the main reason for inadequate control of $\mathrm{BP}$ is poor adherence to both pharmacologic and non-pharmacologic treatment regimens(7). Poor adherence to antihypertensive treatment is estimated to contribute to the lack of adequate blood pressure control in more than two thirds of patients.

When therapeutic response to a drug is not as expected, it is a major challenge for many physicians to decide whether the patient is a non-responder or is non-adherent. Poor adherence is therefore often incorrectly interpreted as a lack of treatment response and failure to detect non-adherence can lead to inappropriate corrective measures being undertaken. Areliable assessment of adherence would have a great impact on medical costs by preventing unnecessary investigations or dose adaptations (8).

Correctly estimating adherence is challenging. Several studies have demonstrated that clinicians' estimate of non-adherence is very poor (8). The various instruments available for estimating adherence include electronic monitoring, pharmacy refill rates, pill counts, drug assays and self-report $(9,10)$. Selfreport has been widely used to assess adherence $(8,9)$, and several instruments have been developed to assess self-reported adherence. These include the Hill-Bone compliance to high BP therapy scale (11), the Morisky instrument, The Compliance Praxis Survey (COMPASS) (12), the MedicalOutcomesStudy (MOS) General Adherence Scale, SHEA and Haynes (9).

The Hill Bone compliance to high blood pressure therapy scale was designed as a simple tool for clinicians to evaluate patient's self-reported adherence levels. It assesses three behavioural domains of high blood pressure treatment: medication taking, appointment keeping and reduced sodium intake. It was designed for self-administration or interviewer-assisted administration and takes about five minutes to complete and it has been validated in various communities including an African setting (13).

No Kenyan data on adequacy of blood pressure control, reasons for lack of control, or level of adherence to antihypertensive medication is currently available. We set out to fill this knowledge void which is paramount in improving our patient management and thus outcomes.

\section{MATERIALS AND METHODS}

A cross-sectional descriptive study was conducted after institutional review board approval at the Kenyatta National Hospital. The study was conducted between 1st June and 30th November 2007.
The calculated sample size was 264, randomly selected patients with hypertension on follow up in the medical outpatient clinics. This was based on an estimated prevalence of adequate BP control of $21.5 \%$. Inclusion criteria included patients who had a prescription of a recognised antihypertensive drug from the clinic with at least one documented renewal of prescription, and had at least two clinic visits prior, to the recruiting visit and gave informed consent. Patients with a known or suspected cause of secondary hypertension were excluded.

History and full physical examination was undertaken by a skilled and trained investigator and was inclusive of anthropometric measures. BP was measured as per the WHO recommendation (14). Details of the patient's treatment were obtained from the file; these included all the drugs the patient was taking, their doses and frequency.

Level of adherence was assessed using the Hill-Bone compliance with high blood pressure therapy medication taking subscale (appendix II). The administration of this was interviewer-assisted with standardised translations. Patients were then classified as adherent or non adherent depending on the total score.

Adequate BP control was defined as a blood pressure of less than $140 / 90 \mathrm{mmHg}$. Both the SBP and DBP had to be below these thresholds for BP to be considered controlled (15). For patients with diabetes, adequate control was defined as a blood pressure of less than $130 / 80 \mathrm{mmHg}$. The poorly controlled patients were further classified according to grade of hypertension (WHO/ISH and ESH/ ESC classification).

\begin{tabular}{lll}
\hline $\begin{array}{l}\text { Grade of } \\
\text { hypertension }\end{array}$ & SBP $(\mathrm{mmHg})$ & $\mathrm{DBP}(\mathrm{mmHg})$ \\
\hline I & $140-159$ & $90-99$ \\
II & $160-179$ & $100-109$ \\
III & $>180$ & $>110$ \\
\hline
\end{tabular}

Adherence was defined as per the Hill-Bone compliance with high blood pressure therapy scale. A patient was defined as fully adherent if they had a score of 8 . A score $\geq 9$ was considered representative of non-adherence. Non-adherence was graded from 9-32, with higher scores reflecting poorer levels of adherence.

All data was analysed using SPSS version 15.0. Analysis involved descriptive statistics such as means for continuous variables and frequency distributions for categorical variables. Comparisons for continuous data were made using the $t$-test and for categorical data using the chi-square test.

Adherence score was analysed as a continuous variable, and correlated to the level of blood 
pressure using Pearson's correlation. The strength of association between adherence score and level of blood pressure was obtained using linear regression. The adherence score was also analysed as a categorical variable using a one way analysis of variance and Spearman rank correlation, and the results were similar to those obtained with analysis of adherence score as a continuous variable. The level for statistical significance utilised was $\mathrm{P} \leq 0.05$.

\section{RESULTS}

Over a six month period between June and November 2007,783 files were screened, $575(73 \%)$ of which met the inclusion criteria and of these, 268 were randomly selected; four were excluded for various reasons (two declined, one was not on medication and their was a language barrier with one) and thus 264 patients were recruited into the study (Figure 1).

Figure 1

Flow chart on screening and recruitment

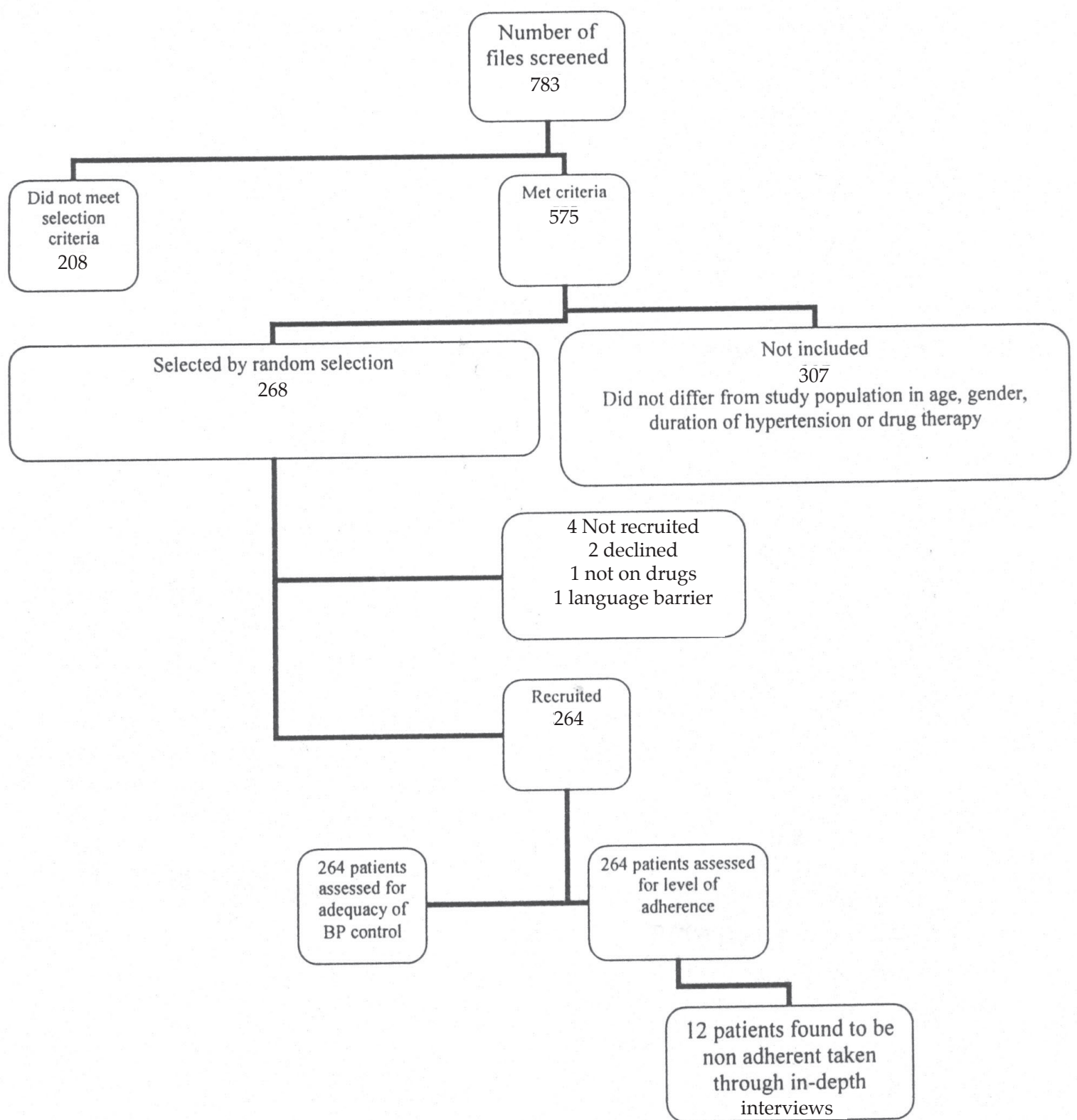


All 264 patients were assessed for both adequacy of blood pressure control and level of adherence with antihypertensive medication. The demographic characteristics of the patients recruited did not differ significantly from thosenot selected (Table1). Females comprised $67.7 \%$, the mean age was 57.26 (range 28-93 years); the mean duration of hypertension was 6.75 years with a range of six months to 31 years. Most of the patients were married, had attained at least primary education and paid for their own medication, with about $31 \%$ being supported by their progeny. Proportion with knowledge of appropriate lifestyle changes was $49.6 \%$ for weight loss, $54.2 \%$ for exercise, $79.8 \%$ for dietary salt reduction and $53.1 \%$ for other dietary measures.

The mean body mass index (BMI) for the group was 29.04 with a range of 16-46: $21.6 \%$ of the group had a normal BMI, $38.2 \%$ were overweight and $40.2 \%$ were obese. The mean waist hip ratio was 0.7 with a range of $0.52-1.28,62.6 \%$ had visceral obesity. $11.1 \%$ were smokers and $3.4 \%$ were diabetic.

Majority of the patients were on more than one antihypertensive drug with $35.2 \%$ on two drugs, $36.6 \%$ on three drugs and $14.9 \%$ on four or more drugs. The commonest drugs used were thiazide diuretics at $64.1 \%$, followed by B-blockers at $55.7 \%$, calcium channel blockers at $55.3 \%$ and angiotensin system inhibitors at $50.4 \%$. Only $19.5 \%$ of the patients were on statins with $10.7 \%$ on aspirin.

Table 1

Demographic and other characteristics of study population

\begin{tabular}{lc}
\hline Mean age (years) & 57.26 (range \\
& $28-93$ years) \\
Male & 59.55 \\
Female & 56.23 \\
Gender (\%) & \\
Male & 32.4 \\
Female & 67.6 \\
Mean duration of & 6.75 (range 6 \\
hypertension (years) & months-35 years) \\
Marital status (\%) & \\
Single & 6.1 \\
Married & 78.2 \\
Divorced & 1.9 \\
Widowed & 13.4
\end{tabular}

\section{Occupation (\%)}

Formal employment $\quad 16.8$

Business 27.9

Farming $\quad 30.9$

Other 23.3

Level of education (\%)

None $\quad 18.3$

Primary $\quad 41.2$

Secondary 29.0

Tertiary 10.3

Medication purchased by (\%)

Self $\quad 62.2$

Employer/insurance $\quad 3.1$

Parent 0.4

Child $\quad 30.9$

Other 0.8

Knowledge of lifestyle

measures in blood pressure

reduction $(\%)$

Weight loss $\quad 49.6$

Reduced salt intake $\quad 79.8$

Exercise $\quad 54.2$

Dietary changes $\quad 53.1$

Mean BMI 29.04

Mean WHR 0.704

(range 0.52-1.28)

The mean systolic blood pressure of the group was $148.3 \mathrm{mmHg}$ (range $90-240 \mathrm{mmHg}$ ), the mean diastolic blood pressure was $92 \mathrm{mmHg}$ (range 50-160). sixty eight patients $(26 \%)$ had BP of $<140 / 90 \mathrm{mmHg}$ hence classified as adequately controlled. Of those whose blood pressure was not controlled, $41.5 \%$ had blood pressure between 140/90-159/99mmHg (gradeI), 37.8\% had blood pressure between $160 / 100-$ $179 / 109 \mathrm{mmHg}$ (grade II), and $19.7 \%$ had blood pressure of $\geq 180 / 100 \mathrm{mmHg}$ (grade III).

There were nostatistically significant differences in the demographic characteristics of the patients with controlled blood pressure and those whose BP was not controlled (Table 2). A trend towards poor blood pressure control in those with longer duration of hypertension was evident however, this did not reach statistical significance $(P=0.06)$. 
Table 2

Characteristics of patients by controlled and uncontrolled BP status

\begin{tabular}{|c|c|c|c|}
\hline & Controlled & Uncontrolled & P-value \\
\hline Age (years) & 59.07 & 56.62 & 0.4 \\
\hline \multicolumn{4}{|l|}{ Duration of } \\
\hline \multicolumn{4}{|l|}{ hypertension } \\
\hline (years) & 5.49 & 7.19 & 0.06 \\
\hline \multicolumn{4}{|l|}{$\mathrm{BMI} \%$} \\
\hline Normal & 31.9 & 17.9 & 0.03 \\
\hline Overweight & 37.7 & 38.4 & \\
\hline Obese & 30.4 & 43.7 & \\
\hline \multicolumn{4}{|l|}{ Gender } \\
\hline Male & $24(28.2 \%)$ & $61(71.8 \%)$ & 0.629 \\
\hline Female & $45(25.4 \%)$ & $132(74.6 \%)$ & \\
\hline \multicolumn{4}{|l|}{$\begin{array}{l}\text { Knowledge of } \\
\text { weight loss }\end{array}$} \\
\hline Yes & $36(27.7 \%)$ & $94(72.3 \%)$ & 0.624 \\
\hline No & $32(25 \%)$ & $96(75 \%)$ & \\
\hline \multirow{2}{*}{\multicolumn{4}{|c|}{$\begin{array}{l}\text { Knowledge of } \\
\text { reduced salt intake }\end{array}$}} \\
\hline & & & \\
\hline Yes & $60(28.7 \%)$ & $149(71.3 \%)$ & 0.083 \\
\hline No & $9(17 \%)$ & $44(83 \%)$ & \\
\hline \multicolumn{4}{|l|}{$\begin{array}{l}\text { Knowledge of } \\
\text { exercise }\end{array}$} \\
\hline Yes & $38(26.8 \%)$ & $104(73.2 \%)$ & 0.897 \\
\hline No & $31(26.1 \%)$ & $88(73.9 \%)$ & \\
\hline \multicolumn{4}{|l|}{$\begin{array}{l}\text { Knowledge of } \\
\text { dietary changes }\end{array}$} \\
\hline Yes & $39(28.1 \%)$ & $100(71.9 \%)$ & 0.501 \\
\hline No & $30(24.4 \%)$ & $93(75.6 \%)$ & \\
\hline \multicolumn{4}{|c|}{ Level of education } \\
\hline None & 33.3 & 66.7 & 0.235 \\
\hline Primary & 22.2 & 77.8 & \\
\hline Secondary & 28.9 & 71.1 & \\
\hline Tertiary & 14.8 & 85.2 & \\
\hline \multicolumn{4}{|l|}{ Occupation } \\
\hline Farming & 30.9 & 69.1 & 0.540 \\
\hline Business & 23.3 & 76.7 & \\
\hline \multicolumn{4}{|l|}{ Formal } \\
\hline Employment & 11.4 & 88.6 & \\
\hline \multicolumn{4}{|l|}{ Marital status } \\
\hline Married & 26.8 & 73.2 & 0.591 \\
\hline Single & 25 & 75 & \\
\hline Widowed & 28.6 & 71.4 & \\
\hline Divorced & 0 & 100 & \\
\hline
\end{tabular}

Weight was significantly associated with blood pressure control status. Normal BMI was associated with good blood pressure control, OR 2.15 (CI 1.094.29, $\mathrm{p}=0.02$ ) and increasing BMI was associated with poor blood pressure control $(p=0.03)$. The mean systolic and diastolic blood pressure rose with increasing number of antihypertensive drugs (ANOVA $p=0.012$ for systolic and 0.038 for diastolic $\mathrm{BP})$.

Thirty one point eight per cent of the patients were found to have a score of eight on the Hill-Bone scale, representing the highest level of adherence. There were no statistically significant differences in the demographic or socioeconomic characteristics of the adherent and non adherent patients (Table 3).

Table 3

Demographic characteristics of adherent compared to non adherent patients

\begin{tabular}{|c|c|c|c|}
\hline & Adherent & Non-adherent & P-value \\
\hline \multicolumn{4}{|l|}{ Gender (\%) } \\
\hline Male & 30 & 70 & 0.52 \\
\hline Female & 25.6 & 74.4 & \\
\hline Mean age (years) & 57.9 & 57.0 & 0.385 \\
\hline \multicolumn{4}{|l|}{ Marital status (\%) } \\
\hline Single & 36.4 & 63.6 & 0.86 \\
\hline Married & 27.2 & 72.8 & \\
\hline \multicolumn{4}{|l|}{ Divorced/ } \\
\hline separated & 20.0 & 80 & \\
\hline Widowed & 24.0 & 76 & \\
\hline \multicolumn{4}{|l|}{ Occupation (\%) } \\
\hline Formal employment & at 14 & 24 & 0.3 \\
\hline Business & 13 & 43 & \\
\hline Farming & 17 & 40 & \\
\hline Other & 8 & 33 & \\
\hline \multicolumn{4}{|c|}{ Level of education $(\%)$} \\
\hline None & 5 & 27 & 0.09 \\
\hline Primary & 25 & 60 & \\
\hline Secondary & 10 & 43 & \\
\hline Tertiary & 12 & 11 & \\
\hline \multicolumn{4}{|c|}{ Medication purchase by $(\%)$} \\
\hline Self & 28.1 & 71.9 & 0.839 \\
\hline \multicolumn{4}{|l|}{ Employer/ } \\
\hline insurance & 42.9 & 57.1 & \\
\hline Parent & 0 & 100 & \\
\hline Child & 24.1 & 75.9 & \\
\hline Other & 0 & 100 & \\
\hline \multirow{2}{*}{\multicolumn{4}{|c|}{$\begin{array}{l}\text { Duration of } \\
\text { hypertension }\end{array}$}} \\
\hline & & & \\
\hline (years) & 6.44 & 6.91 & 0.622 \\
\hline
\end{tabular}

Increasing levels of non adherence as assessed by the Hill Bone (HB) score were significantly associated with increasing blood pressure levels. Analysis by Spearman's rank found a positive correlation of 0.6 between higher HB scores and higher systolic blood pressure (SBP) levels $(\mathrm{p}=0.067)$ and 0.77 between HB 
score and diastolic blood pressure (DBP) $(\mathrm{p}=0.009)$. On linear regression, every unit increase in $\mathrm{HB}$ score was associated with a $4 \mathrm{~mm}$ rise in SBP, $\mathrm{R}$-square $=$ 0.54 and a $3 \mathrm{~mm}$ rise in DBP, $\mathrm{R}$-square $=0.63$.

Fifty one patients representing $19.3 \%$ of the study population were found to be adherent to medical therapy despite demonstrating poor blood pressure control. Forty nine per cent of these patients were on three antihypertensive drug classes, $25.5 \%$ on two drugs, $15.7 \%$ on one drug and $9.8 \%$ on four drugs. However, of these, only seven patients were on maximal doses of three drugs including a diuretic. Thirty five patients $(13.25 \%)$ despite not being adherent to antihypertensive medication had well controlled BP; of note, $82 \%$ of these patients had grade I hypertension at the time of diagnosis.

\section{DISCUSSION}

We report on the first Kenyan BP control study conducted in the general medical out patient clinics of a tertiary referral teaching hospital manned by physicians and medical residents with nostandardised drug management protocols in use. These clinics do however serve as primary care clinics for the Nairobi metropolis with an estimated population of $>3$ million and thus we are confident that our results are referable to a significant proportion of urban Kenyan treated hypertensive patients.

The demographic characteristics of our study patients does not differ significantly from other out patient clinic samples of other chronic diseases at this institution in the recent past. The female gender predominance in our study is a reflection of the documented out patient medical attendance, and is thought to reflect the health seeking habits by females.

Our detected level of BP control of $26 \%$ falls well below the WHO recommended $50 \%$ for community control (16). This is as expected, significantly below that achieved in the setting of clinical trials of $60 \%$ and $90 \%$ control of systolic and diastolic BP respectively (17-19), and 59\% achieved in hypertension specialist clinics in the west (20). In the United States, control rates of as high as $49 \%$ have been reported (3). In an Italian study of 7626 hypertensive patients managed by general practitioners, $48.1 \%$ achieved BP levels $<140 / 90 \mathrm{mmHg}(21)$ in association with adherence rates of $75 \%$.

African data on BP control rates is scarce with generally low control levels being reported predominantly from general population groups: 8\% in an Egyptian study in 1995 (22), 13\% in a 1999 Tanzanian a study (17), $16 \%$ in a South African study (23), and 6.2\% in Ghana in 2006(24). Ourfinding of $26 \%$ is higher than that cited in other African studies, this may be due to the inherent tertiary referral hospital bias in whom BP control can be expected to surpass that of general practice care. However, this bias may indeed be bidirectional with more severe cases of hypertension being referred or seeking tertiary level care.

Majority of our poorly controlled patients (57.5\%) had BP > 160/100 mmHg indicative of the high severity of poor control placing this patient population at high cardiovascular disease risk. The very poor BP control in our population, in the face of high prevalence of hypertension, underlies the growing publichealth challenge of hypertension and the expected epidemic of morbidity and mortality from cardiovascular and renal disease.

Cost effective strategies for primary prevention and treatment of hypertension are urgently needed to minimise this present and emerging scourge.

We report low levels of antihypertensive drug adherence with no regional studies for comparison. Western countries have reported higher levels of adherence with an Australian study using the Morisky score reporting $55.2 \%$ (26) and a USA veteran affairs study reporting $78.3 \%$ (27). In the western countries, adherence was evaluated in groups of patients who had free access to medication and this may account for some of the differences in level of adherence seen in our population.

Our data failed to reveal clear predictors of non adherence, however there was a non significant trend towards poorer adherence with increasing number of medications. Whereas poor adherence in other populations has been associated with black race, lower income and younger age among others (28), in our sample non adherence was not significantly associated with any demographic factor. This may be partly accounted for by the fact that our population was fairly homogenous in socio-cultural, economic and demographic terms.

Associations of poor BP control in our study included non adherence, obesity, lack of lifestyle modification and suboptimal therapy. Not unexpectedly, non adherence was significantly associated with poor BP control in our population, as has been documented previously with a clear cause effect relationship. Ross et al (28) found DBP to be associated with adherence: mean DBP in adherent group was $85 \mathrm{mmHg}$ and $91 \mathrm{mmHg}$ in poor adherent, a statistically significant difference $(\mathrm{P}=0.001)$. Nelson et al (26) found that adherence was associated with significantly lower systolic blood pressure.

Obesity in our data was significantly associated with poor BP control, and was highly prevalent in our samplewith $74.8 \%$ of our study population beingeither overweight or obese. There is conclusive evidence that weight reduction lowers BP in obese patients (29) and thus inexpensive weight loss measures should be a part of hypertension management. 
Lack of lifestyle modification may have contributed to poor BP control, however this was not studied. We only assessed patient's knowledge of lifestyle measures which was considerably high at $50 \%$ for weight loss, exercise and dietary changes and $80 \%$ for reduced salt intake. It has already been shown in multiple studies that lifestyle measures contribute to BP reduction (29). The failure of the knowledge of lifestyle measures to translate into or contribute to better BP control may be partly due to non adherence with the lifestyle measures. However, this was not assessed in this study.

Sub optimal drug choices, drug combinations and doses were found to be associated with poor $\mathrm{BP}$ control. Inadequate drug combinations or failure to achieve optimal doses may have accounted for lack of control in patients who were otherwise adherent to therapy. Suboptimal therapy may be due to therapeutic inertia, which has been described in other studies as the failure of providers to begin new medications or increase dosages of existing medications when an abnormal clinical parameter is recorded (30).

Resistant or refractory hypertension is defined as a blood pressure of at least $140 / 90 \mathrm{mmHg}$ or $130 / 80 \mathrm{mmHg}$ in diabetes or renal disease, despite adherence with full doses of at least three antihypertensive medications, including a diuretic (3). Resistant hypertension could only account for a very small percentage of poor BP control in our study, as only seven patients $(2.6 \%)$ would qualify to be categorised as such.

Our limitations included use of self report to assess adherence which may over estimate levels of adherence, however, our levels of adherence were still low in spite of this. We report very poor blood pressure control in our population and this study underscores the urgent need to revise our blood pressure management practices with the aim of improving control, improving patient education and adherence, emphasizing lifestyle changes and ongoing clinician education.

\section{REFERENCES}

1. Opie, L. H. and Seedat, Y. K. Hypertension in subSaharan African populations. Circulation. 2005; 112: 3562-3568.

2, Sanicki, P. and Gauran, N.M.Have ALLHAT, ANBP2, ASCOT-BPLA and so forth improved our knowledge about better hypertension care? Hypetension. 2006; 48: $1-7$.

3. Chobanian, A.V., Bakris, G.L., Black, H.R., et al. The seventh report of the Joint National Committee on prevention, detection, evaluation and treatment of high blood pressure. J. Am. Med. Assoc. 2003; 289:2560-2572.

4. Whelton, P.K., He, J. and Muntner, P. Prevalence, awareness, treatment and control of hypertension in North America, North Africa and Asia. J. Hum. Hypertens. 2004; 18: 545-551.

5. Cappucio, F., Micah, F., Emmett, L., et al. Prevalence, detection, management and control of hypertension in Ashanti, West Africa. Hypertension. 2004; 43:10171022.

6. Bovet, P., Ross, A., Gervasoni, J., et al. Distribution of blood pressure, BMI and smoking habits in the urban population of Dar es Salaam, Tanzania and associations with socioeconomic status. Int J. Epid. 2002; 31: 240-247.

7 Thrall, G., Lip, G.Y.H. and Lane, D. Compliance with pharmacologic therapy in hypertension: Can we do better, and how? J. Hum. Hypertens. 2004; 18:595597.

8. Burnier, M., Santschi, V., Favrat, B. and Brunner, H.R. Monitoring compliance in resistant hypertension: an important step in patient management. J. Hypertens. 2003; 21(suppl 2): S37-S42.

9. Hamilton, G.A. Measuring adherence in a hypertension clinical trial. Eur. J. Cardiovasc. Nur. 2003; 2: 219-228.

10. Krousel-Wood, M., Thomas, S., Muntner, P. and Morisky, D. Medication adherence: A key factor in achieving blood pressure control and good clinical outcomes in hypertensive patients. Curr. Opin. Cardiol. 2004; 19: 357-362:219-228.

11. Kim, T.M., Hill, M.N., Bone, L.R. and Levine, O.M. Development and testing of the Hill-Bone compliance to high BP therapy scale. Prog. Cardiovasc. Nurs. 2000; 15: $90-96$.

12. Schoberberger, R., Janda, M., Pescosta, W. and Sonneck, G. The Compliance Praxis Survey (COMPASS): a multidimensional instrument to monitor compliance for patients on antihypertensive medication. J. Hum. Hypertens. 2002; 16: 779-787.

13. Lambert, E., Steyn, K., Stender, S., et al. Cross-cultural validation of the Hill-Bone compliance with highblood pressure therapy scale in a South African, primary health care setting. Ethn. Dis. 2006; 16: 286-291.

14. Guideline Subcommittee: 1999 World health Organization-International society of hypertension guidelines for the management of hypertension. J. Hypertens. 1999; 17: 151-183.

15. Edwards, R., Unwin, N., Mugusi, F., etal. Hypertension prevalence and care in an urban and rural area of Tanzania. J. Hypertens. 2000; 18:145-152.

16. Weinehall, L., Ohgren, B., Persson, M., et al. High remaining risk in poorly treated hypertension; the 'Rule of Halves' still exists. J. Hypertens. 2002; 20: 2081-2088.

17. Cushman, W.C., Ford, C.E., Cutler, J.A., et al. Major outcomes in high-risk hypertensive patients randomized to ACE-1 or CCB vs diuretic - The antihypertensive and lipid-lowering treatment to prevent heart attack trial (ALLHAT). J. Am. Med Assoc. 2002; 288: 2981-2997.

18. Kjeldsen, E., Hedner, T., Jamerson, K., et al. Hypertension optimal treatment study, home BP in treated hypertensive patients. Hypertension. 1998; 31: 1014-1020.

19. Black, H.R., Elliot, W.J., Neaton, J.D., Grandits, G. and Grambusch P. for the CONVINCE research group. Baseline characteristics and early blood pressure 
control in the CONVINCE Trial. Hypertension. 2001; 37: 12-18.

20. Singer, M. G., Izhar, M. and Black, H. Goal-oriented hypertension management-translating clinical trials to practice. Hypertension. 2002; 40:464-469.

21. Degli, E., Berto, P., Buda, S., et al. PANDORA project. J. Hum. Hypertens. 2008; 22: 51-53.

22. Ibrahim, M.M., Rick, H., Appel, L., et al. Hypertension prevalence, awareness, treatment and control in Egypt. Results from the Egyptian National Hypertension Project. NHP investigative team. Hypertension. 1995; 26: 886-890.

23. Steyn, K., Fourie, J., Lombard, C., et al. Hypertension in the black community of Cape Peninsula, South Africa. East Afr. Med. J. 1996; 73:758-763.

24. Agyemang, C., Bruignzeels, M. A. and OwusuDabo, E. Factors associated with hypertension awareness, treatment, and control in Ghana, West Africa. J. Hum. Hypertens. 2006; 20: 67-71.

25. Borzecki, A., Wong, A., Hickey, E. et al. Hypertension control. how well are we doing? Arch. Intern. Med. 2003; 163: 2705-2711.
26. Nelson, M.R., Reis, M.C., Ryan, P., et al. Self-reported adherence with medication and cardiovascular disease outcomes in the Second Australian National Blood Pressure Study. MJA 2006; 185: 487-489.

27. Siegel, D., Lopez, J. and Meier, J. Antihypertensive medication adherence in the department of veterans affairs. Am J. Med. 2007; 120: 26-32.

28. Ross, S., Walker, A. and MacLeod, M.J. Patient compliance in hypertension: role of illness perceptions and treatment beliefs. J. Hum. Hypertens. 2004; 18: 607-613.

29. Whelton, P.K., Appel, L.J., Espeland, M.A., et al (for TONE collaboration group) Sodium restriction and weight loss in the treatment of hypertension in older persons: a randomized controlled trial of non phannacologicintervention in the elderly. J. Am. Med. Assoc. 1998; 279: 839-846.

30. Okonofua, E., Simpson, K., Jesri, A., et al. Therapeutic inertia is an impediment to achieving the healthy people 2010 BP control goals. Hypertension. 2006; 47: 345- 351. 